\title{
PELAKSANAAN REWARD DAN PUNISHMENT DALAM MENANAMKAN NILAI-NILAI AGAMA PADA ANAK DI TAMAN KANAK-KANAK ISLAMIC CENTER SAMARINDA
}

\author{
Nurwati \\ Program Studi PIAUD,Jurusan Pendidikan Madrasah, Fakultas Tarbiyah dan Ilmu \\ Keguruan, IAIN Samarinda \\ nurwatinir123@gmail.com \\ Nurul Muawwanah \\ Program Studi PIAUD,Jurusan Pendidikan Madrasah, Fakultas Tarbiyah dan Ilmu \\ Keguruan, IAIN Samarinda \\ muawwanahnurul@gmail.com
}

\begin{abstract}
This study is entitled "The Implementation of Reward and Punishment in instilling religious values in children in the Islamic Center Kindergarten in Samarinda. In the learning process many techniques are used by teachers to achieve learning goals, one of them is using reward and punishment techniques. Kindergarten Islamic Center is one of the Islamic educational institutions that aims to produce a generation of monotheists who adhere to worship in life by introducing God through sentences thoyyibah and Asmaul Husna using Reward and Punishment techniques. So this study aims to find out how the implementation of the provision of rewards and punishments in kindergarten Islamic Center Samarinda.

This research is a descriptive qualitative research that is describing the situation in Islamic Kindergarten. Informants in this study are the principal and teachers. The data collection techniques using the method of observation, interviews and documentation. For the validity of the data using data reduction, data presentation and drawing conclusions or verification. The results showed that in the implementation of rewards and punishments carried out in kindergarten Islamic Center reward and punishment is one of the teacher's techniques to develop aspects of religious values and is given to each activity in accordance with the circumstances. Rewards are given when children are able to follow the rules, children are able to complete tasks well, and children are independent and patient. Reward is given in several forms, namely the form of praise, the form of goods, forms of touch and applause. Whereas punishment is given when the child does not follow the rules, does not complete the task properly, is not being independent and patient. There are several stages of punishment given, namely giving advice, separating children from groups in a few moments and transferring children to other classes.
\end{abstract}

Keywords; Reward and Punishment, Religious Values 


\section{PENDAHULUAN}

Anak merupakan investasi yang sangat penting dalam menyiapkan sumber daya manusia dimasa yang akan datang. Dalam rangka mempersiapkan anak masa depan yang berakhlak mulia, pendidikan merupakan salah satu hal yang saangat penting untuk diberikan sejak usia dini. Memberikan Perhatian kepada anak usia dini untuk mendapatkan pendidikan tepat untuk menyiapkan generasi yang unggul dan beraklak mulia. Salah satu aspek yang harus harus mendapatkan perhatian dalam pendidikan anak usia dini adalah menanamkan nilai-nilai agama.

Pendidikan anak usia dini (PAUD) adalah upaya pembinaan yang ditunjukkan kepada anak usia dini dilakukan dengan pemberian stimulasi melalui program dalam pendidikan yang diarahkan untuk menanamkan nilai-nilai agama pada anak. Menanamkan nilai-nilai agama pada anak adalah kewajiban seorang pendidik Dalam menanamkan nilai-nilai agama pada anak dapat dilakukan dalam bentuk bimbingan, arahan, contoh, perintah, ajakan, dan dorongan yang dilaksanakan oleh pendidik dengan senang, ikhlas, dan penuh kedekatan hati dan fisik.

Penanaman nilai-nilai agama yang dilakukan sejak dini perlu dilakukan untuk membekali anak agar lebih matang menghadapi permasalahan kehidupan. Dalam proses pendidikan yang diselenggarakan di taman kanak-kanak bukan saja pembentukan aspek kognitif dan psikomotoriknya saja akan tetapi lebih pada apektifnya, daalam hal ini penanaman nilainilai agama .

Menurut Tholkhah Hasan (2009:92) bahea penenaman nilai-nilai agama serta pemberian pengalaman beragama yang disebut juga pengalaman dan penghayatan agama, dalam hal ini pendidikan agama lebih menitik beratkan pada internalisasi (penanaman) nilai-nilai agama dan penerapan ajaran agama dalam sikap perilaku. Pembentukan sikap perilaku sangat diperlukan agar nantinya anak memiliki pondasi yang kuat dan tidak mudah terombang-ambing oleh keadaan di masyarakat.

Agar pendidikan dapat tercapai perlu adanya penyelenggaran pendidikan, salah satunya melalui layanan pendidikan Taman Kanak- Kanak (TK) untuk usia 4-6 tahun. Dalam membimbing dan mengembangkan potensi anak perlu menggunakan strategi, metode atau tekhnik pembelajaran yang tepat agar tujuan dapat tercapai. (Soegeng Santoso, 2009:2.11). Pemilihan strategi, metode ataupun tekhnik yang dilakukan pendidik tentunya dilandasi alasan yang kuat dan faktor pendukungnya. Untuk menanamkan nilai-nilai agama pada anak dapat digunakan strategi yang tepat yang memungkinkan terbentuknya kebiasaankebiasaan yang didasari oleh sikap perilaku agar anak dapat menjalani kehidupan sesuai dengan norma yang berlaku sehingga dapat 
diterima oleh sebayanya pada khususnya dan pada masyarakat pada umumnya.

Dalam menanamkan nilai-nilai agama pada anak usia dini disini diharapkan agar semua perilaku anak membentuk suatu pola perilaku yang dapat diterima. Perilaku tersebut ditunjukkan dengan perasaan, tindakan, sikap keyakinan, kenangan atau rasa hormat kepada orang lain.

Taman Kanak-kanak Islamic Center merupakan salah satu lembaga pendidikan islam yang bertujuan untuk menghasilkan generasi bertauhid yang taat menjalankan ibadah dalam kehidupan dengan mengenalkan Allah melalui kalimat-kalimat thoyyibah dan Asmaul Husna. Dalam menanamkan nilai-nilai agama tidak berfokus pada keislaman saja, akan tetapi pelaksanaannya dilakukan di semua sentra yang ada. Sentra yang biasa dikenal dengan Beyond Centers and Cricle Time (BCCT) merupakan model pembelajaran yang berpusat disentra bermain dan ketika anak berada dalam lingkarang. Guru menghadirkan dunia nyata kedalam kelas dan mendororng anak mengorelasi antara pengetahuan yang dimilikinya dengan penerapan dalam kehidupan sehari-hari. (Suyadi dan Dahlia, 2014: 49)

Ada beberapa model sentra yang diterapkan diantaranya: Sentra Balok, Sentra Peran,Sentra Alam, Sentra Persiapan, Sentra Olah Tubuh, Sentra Seni. Di semua sentra yang ada guru menanamkan nilai nilai agama dalam setiap kegiatan bermain sambil belajar. Ada banyak strategi, model maupun tekhnik yang dapat digunakan dalam menanamkan nilai-nilai agama pada anak usia dini diantaranya adalah tekhnik pelaksanaan pemberian reward dan punishment .

$$
\text { Pemberian reward dan }
$$
punishmentbisa mengasosiasikan perbuatan dan kelakuan seseorang dengan perasaanbahagia, senang dan biasanya akan membuat mereka melakukan suatu perbuatan yang baiksecara berulang ulang selain motivasi.(Kompri, 2015: 289)

Berkaitan dengan reward, dalam AlQur'an juga terdapat ayat-ayat yang mengisyaratkan penggunaan hadiah/pahala dalam mendidik. Salah satunya ialah Q.S Al Imran ayat 136 :

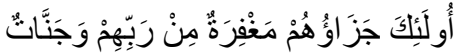

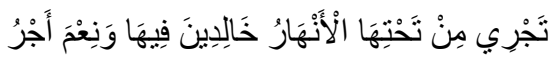

$$
\begin{aligned}
& \text { الْعَامِلِين (ال عمر ان: 3: 136 13: }
\end{aligned}
$$

Terjemah: "mereka itu balasannya ialah ampunan dari Tuhan mereka dan syurga yang didalamnya mengalir sungaisungai, sedang mereka kekal didalamnya, dan itulah sebaik-baik orrang beramal" (QS. Ali Imran: 136) (Departemen Agama RI,2008: 68)

Ayat diatas merupakan bentuk pengakuan terhadap pemberian hadiah atau pahala dalam rangka pendidikan dan pembinaan umat. Pemberian hadiah atau pahala ini diberlakukan kepada sasaran pembinaan yang bersifat khusus. Yakni hadiah bagi yang patuh dan menunjukkan perbuatan baik.

Sedangkan punishment dalam pandangan islam, merupakan hal penting dalam mendidik. Bekenaan dengan hukuman, dijumpai beberapa ayat dalam AlQur'an, salah satunya ialah: 


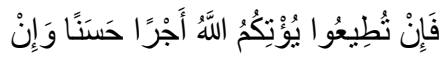

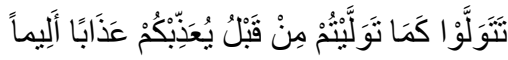

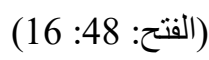

Terjemah: "Maka jika kamu patuhi

(ajakan itu) niscaya Allah akan memberikan kepadamu pahala yang baik dan jika kamu berpaling sebagaimana kamutelah berpaling sebelumnya, niscaya dia akan mengazab kamu dengan azab yang pedih" (QS.Al- Fath:16) (Departemen Agama RI,2008:513)

Ayat tersebut selain mengakui keberadaan hukuman dalam rangka perbaikan umat manusia, juga menunjukkan hukuman itu tidak diberlakukan kepada semua umat manusia melainkan diberlakukan kepada manusia-manusia yang melakukan pelanggaran saja. Manusia yang model seperti ini biasanya sudah sulit diperbaiki hanya dengan nasehat atau teladan. Melainkan harus lebih berat lagi yaitu dididik dengan menggunakan hukuman.

Guru Taman Kanak-kanak (TK) Islamic Center Samarinda melaksanakan prmberian Reward dan punishmentdalam mengembangkan prilaku anak. Berdasarkan latar belakang diatas peneliti tertarik untuk melakukan penelitianBagaimana Pelaksanaan reward dan punishment di Taman Kanak-kanak (TK) Islamic Center Samarinda. Tujuan penelitian ini adalah untuk mengetahui Bagaimana Pelaksanaan Reward dan Punishment di Taman Kanakkanak Islamic Center Samarinda.

\section{METODE PENELITIAN}

Sesuai dengan permasalahan yang diteliti maka jenis penelitian yang digunakan dalam penelitian ini adalah penelitian kualitatif yang bertujuan untuk menghasilkan data yang menggambarkan pelaksanaan Reward dan Punishment di Taman kanak- kanak Islamic Center Samarinda. Penelitian dilaksanakan di Taman Kanak-kanak Islamic Center di kota Samarinda Provinsi Kalimantan Timur.

Adapun teknik pengumpulan data dalam penelitian ini dilakukan secara langsung di lapangan dengan teknik pengumpulan data yang menggunakan terknik observasi, wawancara dan dokumentasi.

Analisis data dilakukan dengan mencari dan menyusun secara sistematis data yang diperoleh dari hasil wawancara, catatan lapangan dan dokumentasi, dengan cara mengorganisasikan data ke dalam kategori, menjabarkan ke dalam unit-unit, menyusun dalam pola, memilih mana yang penting dan yang akan dipelajari, dan membuat kesimpulan sehingga mudah dipahami oleh diri sendiri maupun orang lain.Langkah-langkah yang digunakan adalah reduksi data, penyajian data dan penarikan kesimpulan.

Dalam pemeriksaan keabsahan data peneliti menggunakan teknik triangulasi. Triangulasi yaitu tekhnik pemeriksaan keabsahan data yang memanfaatkan sesuatu lain diluar data itu untuk keperluan 
pengecekan atau sebagai pembanding data yang diperoleh untuk mengcross check kepercayaan suatu informasi yang diperoleh melalui waktu dan alat yang berbeda.

\section{HASIL PENELITIAN DAN}

\section{PEMBAHASAN}

1. PelaksanaanReward

PelaksanaanReward diberikan ketika anak mampu melakukan suatu kebaikan, mampu mengikuti aturan, mampu menyelesaikan tugas dengan baik, mampu bersikap mandiri, mampu bertanggung jawab dan menunjukkan sesuatu yang baik. Bentuk reward yang diberikan di taman kanak-kanak islamic center yaitu;

a. Reward berupa Ucapan diberikan berupa kalimat-kalimat thoyyibah, asmaul husna dan kalimat-kalimat positif seperti; kata masya Allah digunakan untuk mengungkapkan

kekagumanketika anak datang kesekolah dengan senyuman dan menyapa guru serta teman, kataAlhamdulillah saat anak mampu mengikuti aturan dengan berbaris rapi, kata Allah Al Qowi diberikan saat memberi motivasi kepada anak, kata Allah Ar Razaq kata yang tepat untuk membiasakan anak untuk selalu bersyukur, kata Allah Ar-Rasyid di gunakan dalam bentuk doa memohon agar di bimbing atau diberi petunjuk yang tepatdiberi kecerdasan agar melakukan sesuatu sesuai dengan tempatnya dan selalu di bimbing olah Allah SWT., kata Allah Al Alimmemberikan pengertian bahwa dalam hidup kita harus banyak-banyak mencari ilmu dan terus menerus belajar tetapi jangan sampai merasa paling pandai serta mengetahui hanya allah pemilik segala ilmu., kata mendapat pahalabiasanya diberikan saat anak membaca ikrar dengan khusyuk dan mampu membaca doa sebelum dan sesudah kegiatan dengan khusuk., Kata bagus, pintar dan hebat adalah kata positif yang menunjukkan apa yang dilakukan anak sudah benar. Kata ini biasanya di gunakan ketika anak mampu menjawab pertanyaan, melakukan kegiatan sesuai dengan arahan guru, dan mampu menyelesaikan tugas dengan baik, bersikap percaya diri dengan berani tampil di depan umum memimpin membaca doa.

b. Reward barang jarang digunakan hanya sesekali saja dan tidak semua guru memberikan reward jenis ini. Barang yang diberikan hanya berupa sticker berbentuk bintang dan diberikan ketika anak belajar berhitung atau menulis di rumah.

c. Reward berupa Sentuhan adalah Reward yang memberikan reward fisik seperti mengelus kepala anak, tos, 
tepuk tangan dan merangkul anak. reward ini bertujuan agar anak merasa lebih dihargai, merasa aman dan membangun percaya diri anak. reward yang diberikan seperti tepuk tangan menghimbau anak lain untuk tepuk tangan atas penampilannya hari ini itu membuat dia bangga dan diberikan kasih sayang, sentuhan, intinya anak merasa dihargai. Pemberian reward jenis ini diberikan ketika anak percaya diri tampil didepan kelas, menulis nama saat absen, mampu bekerja sama dan bermain bersama teman.

d. Reward pantomimik senyuman atau isyarat bahwa yang dilakukannya benar,seperti ketika anak percaya diri tampil didepan kelas, menulis nama saat absen, mampu bekerja sama dan bermain bersama teman, Pemberian reward ini juga diberikan saat anak mengingatkan teman yang tidak mengikuti aturan, saat anak bertanggung jawab dengan barang dan mainannya, saat anak menawarkan bantuan, dan saat anak mengikuti aturan.

e. Reward tulisan seperti stempelyang bertulisan Good Work, Very good, Perfect, dan stempel berbentuk bintang, diberikan saat anak mampu menyelesikan tugas hasil karya seperti melukis, menggambar, menulis, dan menempel.

\section{Pelaksanaan Punishment}

Punishment yang diberikan di taman kanak-kanak Islamic Center dengan cara; a. Menasihati atau mendoakan ketika anak tidak mengikuti aturan dengan mengingatkan kembali aturan yang telah disepakati, saat anak menangis ditinggal oleh orang tua maka di berikan nasihat dengan memberikan memberikan motivasi, saat anak tidak mengikuti senam diberikan nasihat dengaan menjelaskan bahwa senam sangat bermanfaat untuk kesehatan, saat anak tidak bertanggung jawab dengan barangnya maka di ingatkan kembali sikap tanggung jawab, saat anak tidak mengkuti arahan guru dinasihati sambil mengucapkan istighfar, saat anak terlalu berisik saat kegiatan dinasihati Allah $\mathrm{Al}$ Lathif menyukai kelembutan, tidak mengantre saat kegiatan atau cuci tangan maka didoakan agar bersikap sabar, menghambur mainan saat di sentra disuruh untuk bertanggung jawab merapikan, dan ketika menganggu sahabat yang lain maka dinasihati agar tidak menyakiti teman.

b. Memisahkan dari kelompok adalah tahap Punishment yang kedua. Tahap ini diberikan kepada anak Setelah dinasihati berulang kali dan masih mengulagi kesalahan tersebut maka anak di pisahkan dari kelompok atau disuruh untuk duduk di pojok kelas 
sambil membaca istighfar sampai anak mampu bersikap sabar.

Namun jika kesalahan anak seperti memukul maka langsung diminta untuk duduk dipojok dan menjelaskan masalah yang terjadi lalu di selesaikan sampai anak minta maaf.

c. Memindahkan ke kelas lain adalah tahap terakhir dalam pemberian Punshment, tahap ini diberikan jika anak sudah berulang kali di nasihati, sudah duduk dipojok dan membaca istighfar tetapi masih mengulangi kesalahan. Punishment ini jarang gunakan karena tahap kedua saja sudah cukup untuk membuat anak tidak mengulangi kesalahan tersebut.Saat dipindahkan ke kelas lain anak di minta untuk belajar bersabar dengan guru dan anak kelas lain. Jika anak Kelas A maka di pindah ke Kelas Playgruop, jika anak kelas B maka di Pindah ke kelas A, artinya anak akan dipindah kekelas yang lebih kecil. Setelah beberaapa menit dikelas lain, lalu guru mejemput anak tersebut dan menanyakan sudah bisa bersabar atau belum.

Dalam pemberianReward diberikan ketika anak melakukan suatu kebaikan atau keberhasilan.Sesuai dengan pendapat dari Elizabeth Prima yaitu "Reward adalah suatu perbuatan yang bersifat postif dengan memberikan suatu dorongan agar anak mau melakukan yang baik." Pemberian reward mampu membantu perkembangan aspek- aspek anak usia dini dalam mengembangkan aspek Agama dan moral, sosial.

Sedang pemberian punishment ada teori yang menjelaskan bahwa: "Dalam teori behaviorisme Thorndike efek dari punishment belum tentu menghilangkan atau mengurangi perilaku.(JhonW.Santrock, 2008 : 276), Jadi pemberian punishment tidak selamanya efektif atau dapat mengulangi kembali kesalahan tersebut. Namun pemberian punishment juga membantu mengembangkan aspek sosial anak dan agama moral, saat anak tidak mampu bersabar maka diberikan punishment anak akan belajar bersabar atau menahana dirinya. Dan ketika anak tidak mengikuti aturan lalu diberikan nasihat lalu anak akan mengingat kembali aturan dan memahami kembali aturan tersebut.

\section{Kesimpulan}

Berdasarkan hasil penelitian, dapat disimpulkan sebagai berikut; pelaksanaanreward dan punishment adalah salah satu teknik yang digunakan guru untuk mengembangkan aspek-aspek perkembangan dan diberikan pada setiap kegiatan sesuai dengan situasi dan kondisi. Reward diberikan ketika anak mampu mengikuti aturan, anak mampu menyelesaikan tugas dengan baik, dan anak bersikap mandiri dan sabar. Reward yang diberikan dalam bentuk pujian seperti kalimat thoyyibah, kalimat positif, asmaulhusnaReward yang diberikan dalam bentuk 
pujian seperti kalimat thoyyibah, kalimat positif, asmaul-husna, Reward dalam bentuk barang seperti stempel dan sticker, reward dalam bentuk barang hanya untuk hasil karya anak seperti hasil menggambarr dan menulis dan reward dalam bentu sentuhan seperti mengelus kepala, tos, dan tepuk tangan.

Sedangkan punishment diberikan ketika anak tidak mengikuti aturan, tidak menyelesaikan tugas dengan baik, tidak bersikap mandiri dan sabar. Punishment yang diberikan ada beberapa tahap yaitu dengan memberikan nasehat untuk menjelaskan konsekuensi dari sikap anak, memisahkan anak dari kelompok dalam beberapa saat untuk meredam keaktifan anak tersebut, memindahkan anak ke kelas lain untuk membuat anak lebih bersabar dan menyadari kesalahannya.

Dari simpulan disarankanagar guru memperkaya lagi reward dalam bentuk asmaul husna atau bisa menambah hadits dan ayat Al- Qur'an .Sebaiknya guru harus lebih sering mengingatkan aturan sebelum kegiatan bermarmain sambil belajar.

\section{DAFTAR PUSTAKA}

Departemen Agama RI. Al-Qur'an \& Terjemahan. Bandung: Diponegoro, 2008.

Echlos Jhon M., Shadily Hassan.. Kamus Inggris Indonesia. Jakarta: PT Gramedia Pustaka Utama, 2010.

Kompri, Motivasi Pembelajaran Prespektif Guru dan Siswa. Bandung: Remaja Rosdakarya,2015.
Priyanto S , Ananda S. Kamus Lengkap Bahasa Indonesia. Surabaya: Kartika Putra Press, 2010.

Santoso, Soegeng. Dasar-Dasar Pendidikan TK, Jakarta: Universitas Terbuka, 2009

Santrock, Jhon W. Psikologi Pendidikan, Jakarta: Kencana, 2008.

Sugiyono. Metode Penelitian Pendidikan “ Pendekatan kualitatif, Kualitatif, dan $R \&$ D’. Bandung: ALFABETA, 2010.

. Memahami Penelitian Kualitatif. Bandung: PT Alfabeth, 2010

Suyadi, Dahlia. Implementasi dan Inovasi Kurikulum Paud 2013. Bandung: PT. Remaja Rosdakarya, 2014

Atul Musfiroh, Imroh. "Pemikiran Pendidikan Islam Perspektif Al- Ghazali”, dalam Jurnal Syamil no. 1, Vol. 2, 2013.

Hermoyo, R. Panji. "Membentuk Komunikasi yang Efektif pada Masa Perkembangan Anak Usia Dini", dalam Jurnal Pedagogi, Nomor 1, Volume 1, 2014.

Monoarfa, Rapi. "Penerapan Reward and Punishment dalam Peningkatan Disiplin Kehadiran Mengajar Guru di SDN 03 Duhiada", dalam Jurnal Pendidikan, Sosial dan Budaya, no. 4, Vol. 4, 2018.

Prima, Elizabeth. "Metode Reward dan Punishment dalam Mendisiplinkan Siswa Kelas IV di Sekolah Lentera Harapan Gunung Sitoli Nias." dalam Jurnal Pendidikan Universitas Dhyana Pura, no.1, Vol. 2, 2016

Utami, Tri. "Penanaman Kompetensi Inti Melalui Pendekatan Saintifik di Paud Terpadu An Nur", dalam Jurnal Pendidikan Anak Usia Dini Yaa Bunayya, no. 1, Vol. 2, 2017. 